\title{
Self-efficacy, Autonomy and the Relationships Towards to English Achievement
}

\author{
Shuya Xiao ${ }^{1}$

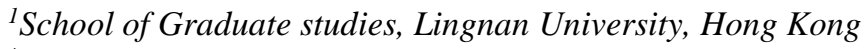 \\ ${ }^{*}$ Corresponding author. Email: shuyaxiao@ln.hk
}

\begin{abstract}
Self-efficacy is an influential variable on learner's autonomy, this study reviewed Self-efficacy, autonomy and the relationship about these two important concepts in the area of English learning. The study would explore whether students' beliefs in their potential strongly related to their responsibilities as autonomous learners in most researches, and whether students with higher Self-efficacy tend to become autonomous learners and have better achievement.
\end{abstract}

Keywords: Self-efficacy, Autonomy, Foreign Language Learning

\section{INTRODUCTION}

\subsection{Social Background}

With the development of globalization, more and more people choose to learn one or even more languages. As a result, more and more researches started to focus on language learning. As one of the major required subjects, English Achievement plays a vital role for adolescents in China. Lots of studies focused on the factors to help students' English Achievements. Self-efficacy and Autonomy become two significant factors in the field of language learning.

Most studies mainly researched second language learners in native speaking countries. This Literature review will introduce these theories and studies to the researchers who have would like to study the relationships between Self-efficacy, Autonomy and English achievement in China; and to exam whether the results would be different when students study English as a foreign language not a second language.

\subsection{Autonomy in Language Learning}

Fostering learner's autonomy becomes one of the most important goals in language teaching. At the same time, students' autonomy also becomes one of the prerequisite in language learning. Holec [1] defines learner autonomy as "the ability to take charge of one's own learning". Autonomous learners are the people with full self-responsibilities who make all their decisions in their learning processes. Learners who have high autonomy have the following abilities; setting goals, choosing study materials methods and techniques, regulating studying process, and evaluating their own results [1] . After Holec raised this concept, autonomy has attracted great concern in the field of foreign language education and many researchers start to focus on learner autonomy.

\subsection{Self-efficacy in Language Learning}

According to Bandura [2] , self-efficacy is a determining element in human behavior, an important factor to affect learner autonomy; self-efficacy can motivate and regulate students' learning. Self-efficacy plays an important role in learners' inherent ability, past achievements and future performances.

Bandura [3] stated that researchers should measure self-efficacy in specific tasks to avoid generality. Language learning differs from other subjects in school. More specially, foreign language learning is also different from native language learning when the researchers explore the development of self-efficacy and the factors affect their Self-efficacy.

\subsection{Research questions}

This research would explore the following questions in the field of language learning. 1) How does Selfefficacy affect students' Achievement, especially in Language learning? 2) What is Autonomy? What are the basic theories about autonomy? 3) What is autonomous 
leaner in English learning? 4) How does Self-efficacy relate to Autonomy in English learning?

\section{LITERATURE REVIEW}

\subsection{Self-efficacy}

Self-efficacy, as a performance-based measure of perceived capability, refers to "beliefs in one's capabilities to organize and execute the courses of action required to produce given attainments" [2] .

From the perspective of social cognitive, human achievement depends on interactions between one's behaviors, personal thoughts and beliefs, and environmental conditions[3]. According to Bandura [2], self-efficacy determines human motivation; at the same time, outcome expectancies and efficacy expectancy determines people's self-efficacy. Bandura [4] defined an outcome expectancy as one's value and belief that a given behavior would lead to particular outcomes; an efficacy expectation as the belief of one person can successfully execute actions and make efforts for achieving their goals.

\subsection{Previous Research on Self-efficacy}

Self-efficacy beliefs have received increasing attention in last two decades. Albert Bandura [4] is the first person who introduced "Self-efficacy", and he provided guidelines for measurement of self-efficacy beliefs for different domains of functioning based on a large theoretical framework known as the social cognitive theory.

Bandura [2] stated that people have five capabilities to determine their behavior; capability, forethought capability, Self-regulatory capability, vicarious capability, and Self-reflective capability. Bandura believed that Self-reflective capability plays the most important role to determine people's behavior among these five capabilities. Self-efficacy means students' beliefs and judgments about their capabilities to successfully perform tasks; it is a key predictor of success as the most powerful arbiters of Self-reflection [2]. As a consequence, students' beliefs about their abilities to accomplish tasks could strongly influence their actual achievements.

Most researchers believe that Self-efficacy influences people's decision making and action; people are willing to attempt tasks that they believe they could accomplish and tend to avoid those they believe exceed their capabilities [5]. As a strong predictor of success; Selfefficacy beliefs determine the effort people would expend, the length people would persist and how resilient they will be when facing difficulties in the tasks. People with higher the sense of efficacy means they would have the greater the effort, persistence, and resilience in their tasks [2].

Self-efficacy affects human functioning through four major psychological processes; cognitive process, motivational process, affective process and selection process [2]. For the process of selection, Bandura [2] believed that people create or shape the environments around themselves through their beliefs. The process of selection determines the direction of people's personal development. As the corresponding of four processes, Bandura [2] believed that four sources would influence Self-efficacy beliefs: mastery experience, vicarious experience, social persuasion, and physiological states.

\subsection{Self-efficacy and Achievement}

The relationship between self-efficacy and academic achievements has been a major focus in the educational field. More and more researchers state that students' Self efficacy have great contributions to increase their academic performances [6].

Based on Collins's research in 1982, beliefs can predict performance better than their real ability. Collins [7] explored the relationship between Self-efficacy and Children's mathematical performances in three different levels of mathematical ability. The result showed that children with higher Self-efficacy in their abilities "solved more problems... and did so more accurately" than children with lower Self-efficacy. The results were the same no matter which level of ability group the students were [7]. The research proved the one statement that Self-efficacy could predicted the students' positive attitude. It means students performed poorer in tasks than others with the same actual abilities might be they lack the efficacy to use all the abilities they have when they are facing real difficulties and challenges [7].

Raoofi, Tan and Chan [8] explored thirty-two studies about Self-efficacy in foreign language Learning context. They concluded the effects of Self-efficacy and factors that affects Self-efficacy in the context of foreign language learning. All the studies showed that Selfefficacy strongly related to students' performances in language tasks as the most influential independent variable expect one study in Thailand [8].

\subsection{Autonomy}

The word autonomy derives from the Latin "autos" meaning "self" and "nomos" meaning "rule". Autonomy, or becoming one's own person through self-directed thoughts, beliefs, and desires, is an important developmental achievement in adolescence [9]. Researchers have proposed different definitions of autonomy [9]. All the definitions can be generalized into two directions: 1) emphasizing freedom from the dependency on others, 2) focusing on freedom to make 
choices, pursue goals, and regulate one's behavior, emotion, and cognition [9].

\subsection{Previous Studies on Autonomy}

Autonomy has been conceptualized as a universal human need, and particularly important for adolescent development. Moreover, a lot of research on adolescent development has focused on autonomy. Since autonomy is a significant issue for adolescent development, it is described as a developmental task, even as a prerequisite to adulthood [10].

\subsection{Views on Autonomy and Its Development}

Adolescents were viewed as moving away from their parents in order to achieve separation and a sense of individuality [10]. In the past several decades, developmental theory developed to the current concept that autonomy development consists of the ability of adolescents to make their own decisions and develop their independent thinking while still engaging in family life and maintaining appropriate relationships with family members, such as parents [9]. Thus, within the autonomy as agency perspective, adolescents are not moving away from their parents, but just moving towards becoming more independent [10].

\subsection{Three Components of Autonomy}

As the autonomy as agency perspective developed, theorists and researchers have distinguished multiple dimensions of autonomy, most commonly including cognitive, emotional, and behavioral components [11]. The development of behavioral, emotional and cognitive autonomy during adolescence is a process through which an adolescent becomes an adult with positive mental health, high self-esteem, positive self-concept, and selfmotivated, self-initiating, and self-regulating [11]. However, the nature of the interrelations among behavioral, cognitive, and emotional autonomy and whether all three are equally significant components of adolescent psychosocial development is an area that requires further research [9].

\subsection{Autonomy in Learning}

As the first person who point out the concept of Learners Autonomy, Holec [1] stated that learner's autonomy is "the ability to take charge of one's own learning.... To take charge of one's own learning is to have, and to hold, the responsibility for the decisions concerning all aspects of this learning". From Holec's perspective, autonomous learners are the people with full self-responsibilities who make all their decisions in their learning processes. Learners who have high autonomy have the following abilities; setting goals, choosing study materials methods and techniques, regulating studying process, and evaluating their own results [1].

\subsection{Autonomy and Self-efficacy in Language Learning}

Based on Cotteral's research [12], Students' selfefficacy highly correlated with their actual performance during autonomous learning. Cotteral [12] explored that the key factors of English Language learners' belief, and She found the students in her study who had high Selfefficacy related to characters which autonomous learners would have. In other words, the confidence of these students in their ability to learn English and the ability to accomplish more could predict autonomous learning. Cotteral [12] found that students who had great beliefs behaved more autonomous in various strategies such as setting goals and planning their English learning processes, even they didn't master these strategies. This result differed from researchers' hypothesis that leaners only interested in familiar and skilled strategies.

Bandura [2] stated that students with high Selfefficacy kept up strategic thinking to search better solutions when they faced failures. In contrast, those students with low Self-efficacy usually ended up directing their efforts ineffectively.

Self-efficacy also highly relates to language learners' self-evaluation. Raoofi, Tan and Chan [8] found the similar results on Self-efficacy and attributions across cultures and areas in different language learning studies; Self-efficacy affect students to make attributions for their success and failure in language learning tasks. Students who have high Self-efficacy tend to attribute their failures to personal reasons that they could have controls about themselves such as their efforts and the strategies they used in the tasks. However, for students who have low Self-efficacy, they attributed their failures to external reasons such as their teachers.

\section{METHODOLOGY}

\subsection{Participants}

The participants (ages 11-15) will be recruited from two junior high schools in two cities. The final sample is expected to be around 300 students in total.

\subsection{Measurement}

Personal Data Questionnaire: The questionnaire provided background information on the participant's: age, year in school, gender, familial status. It is designed to use in this study.

Self-efficacy Questionnaire in English learning: This scale has three factors and 20 items. The Cronbach alpha index of the overall scale was 0.8367 (higher than .7), and 
it showed that the reliability of the questionnaire was acceptable.

Autonomy Questionnaire in English learning: The questionnaire has four aspects and 28 items. The questionnaire items are derived from Boud's questionnaire with the contents.

\subsection{Procedure}

In China, students often do not move between classes for different lessons. A single classroom is used for a group of students who are in the same grade. Each class has a homeroom teacher (normally he or she is an instructor for the class). The information about this study will present to the students by the researcher with homeroom teachers help in classes. The students who want to participate the study will receive a parental consent form and participant form (both of them will be sealed in one envelope) and take them back home. Only students who have the guardians' signatures can be participants in the study.

The researcher will scheduled 50 students with 25-30 minutes as a group each time. During the first 2-5 minutes, the researcher will give a brief instruction for all the participants. All the questions will be presented in computer labs for students.

\subsection{The Description of the Statistical Tests}

This study will use correlation regression to look at the relationships between emotional autonomy and family support, emotional autonomy and academic achievement; and linear regression to look at the correlations between academic achievement, family support and emotional autonomy in the sample.

\section{CONCLUSION}

People's behavior associates with their beliefs about their capabilities rather than their actual capabilities. These beliefs determine the levels of effort that people would like to make to achieve their goals. In the past decades, lots of studies have studied Self-efficacy in different subjects towards to students' achievement, but few of them relate to the area of foreign language. In the last several years, more and more researchers start to research and believe that Self-efficacy plays important role in foreign language learners' positive attitude, efforts, goal setting, and the motivations to learn and regulate themselves [8].

In language learning, having such awareness of one's knowledge and skills can help students to manage their language learning processes effectively and eventually become autonomous learners. By having a sense of their capability, students would have better understanding of setting their goals, choosing the strategies to achieve their goals, regulating and evaluating themselves in their learning process [13].

\section{REFERENCES}

[1] Holec, H., Autonomy and foreign language learning. Communicative Competence, 1981, pp.65.

[2] Bandura, A, Self-efficacy: The exercise of control,New York: Freeman,1997.

[3] Bandura, A, Fearful expectations and avoidant actions as co-effects of perceived self-inefficacy, American Psychologist, 41(12),1986, pp.1389-1391.

[4] Bandura, A, Self-Efficacy: Toward a Unifying Theory of Behavioral Change, Psychological Review, 1977, pp.191-215.

[5] Relich, J. D., Debus, R. L., \& Walker, R., The mediating role of attribution and self-efficacy variables for treatment effects on achievement outcomes, Contemporary Educational Psychology, 1986,11(3), pp.195-216.

[6] Schunk, D. H. Self-efficacy and achievement behaviors. Educational Psychology Review, 1(3), 1989. pp.173-208.

[7] Collins J L, "Self-efficacy and Ability in Achievement Behavior", Paper presented at the meeting of the American Educational Research Association, New York, 1982.

[8] Raoofi, S., Tan, B. H., \& Chan, S. H., Self-efficacy in second/foreign language learning contexts, English Language Teaching, 2012, 5(11).

[9] Zimmer - Gembeck, M. J., \& Collins, W. A. Autonomy Development During Adolescence. Blackwell Handbook of Adolescence. Blackwell Publishing Ltd. 2003.

[10] Beyers, W., Goossens, L., Vansant, I., \& Moors, E., A structural model of autonomy in middle and late adolescence: Connectedness, separation, detachment, and agency, Journal of Youth and Adolescence, 32(5),2003, pp.351-365.

[11] Sessa, F. M., \& Steinberg, L., Family Structure and the Development of Autonomy During Adolescence, Journal of Early Adolescence, 1991,11(1), 38-55.

[12] Cotterall, S, Key variables in language learning: what do learners believe about them?, System, 27(4), pp.1999,493-513. 